\title{
DESIGN AND IMPLEMENTATION OF A MICROCONTROLLER-BASED ADJUSTABLE VOLTAGE AUTOMATIC BATTERY CHARGER
}

\author{
0. O. Odia', ${ }^{1,}$ and J. Okpor ${ }^{2}$

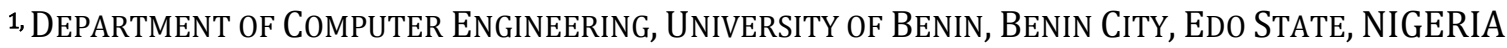

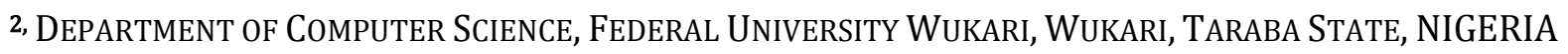 \\ Email adresses: ${ }^{1}$ odia.osasuyi@uniben.edu, ${ }^{2}$ okporjames@fuwukari.edu.ng
}

\begin{abstract}
Battery chargers come in different shapes, sizes and capacities, but it is difficult (if not rare) to find one charger unit that regulates overcharge and can charge different battery voltages. This work uses the basic electrical principles and ICs, to design a user friendly charger circuit that manually adjusts the voltage depending on the voltage of the battery, (6volts, 9volts and 12volts was considered because it is generally available). The circuit charges in three modes namely: Burst charging, trickle charging and pulse charging. It also incorporates a Liquid Crystal Display (LCD) to display the voltage that is being charged. The circuit also uses a Pulse Width Modulator (PWM) in order to control the duty cycle and voltage. The circuit also has an overcharge and over discharge protection. This remarkable charger saves the user time and resources needed to purchase three different chargers for three batteries, with different voltages. From the result obtained the built battery charger was able to charge $6 \mathrm{volts}(10 \mathrm{Ah}), 9 \mathrm{volts}$ (1200mAh) and 12 volts (10Ah) battery to 100\% state of charge. The charging time for the 6volts battery was 2hours 24 minutes, 2 hours 36 minutes for the 9 volts battery and 2 hours 30 minutes for the 12 volts battery.
\end{abstract}

Keywords - Burst Charge, Depth-Of-Discharge DOD, Pulse Charge, State-Of-Charge SOC, Trickle charge, Duty Cycle.

\section{INTRODUCTION}

Battery and charger must go together like a horse and carriage [2] that is why battery charging systems have been intensely researched and developed since the invention of rechargeable batteries. However, due to the increasing demand on energy storage systems in recent applications, automatic battery charger circuits have opened new doors for research and development to meet the needs of the ever growing crave for alternative power sources.

A battery charger or recharger is a device used to put energy into a secondary cell or rechargeable battery by forcing an electric current through it. Basically $\mathrm{A}$ charger performs three functions: (1) delivering charge to the battery; (2) optimizing the charge rate; and (3) terminating the charge [6]. Charging a battery correctly and protecting it against over/undercharging makes a considerable difference in prolonging its service life. By using the most efficient charging methods, it is possible to achieve a long battery service life and short charging times [2]. In order to achieve maximum efficiency and cost-effectiveness from the battery it is essential to ensure that the battery is fully charged. To do this it is not only necessary to choose battery chargers that can recharge batteries in a short time but also to detect when the battery is in the fully charged state [8]. The charging protocol depends on the size and type of the battery being charged. The background of battery charger circuits is as old as the evolution of rechargeable battery itself. When these chargers were built, they would take lots of time before it achieved $100 \%$ SOC. As time passed, Researchers made improvements on this drawback and other drawbacks like: Overcharging [10], short service life, reduction in the Depth Of Discharge [5], a charger with pulse charging feature was constructed to periodically charge the battery upon self-discharge [6], even an automatic battery charger that ejects the battery when it reaches $100 \%$ SOC[10]. Different battery charger methods have been developed by numerous researchers for example, [10] designed an alternative battery charging control technique based on fuzzy logic for photovoltaic (PV) applications where the PV module is connected to a buck type DC/DC power converter and a microcontroller based unit is used to control the lead acid battery charging voltage. A Battery Charger Interface Pre-charge (BCIP) for mobile phone which allows the control of the charge of the battery with the 
maximum battery autonomy without reducing its life was designed and analyzed in [7]. In [10] a battery charger that stops and blows a buzzer upon $100 \%$ SOC was designed.

The conventional battery chargers available in market have limited features. And sometimes they do not monitor the battery health properly, and may let the battery to undergo deep discharge or overcharge [9]. From extensive literature review carried out, it is difficult to find a battery charging circuit that has three types of charge in one circuit - the normal charge, the trickle charge and the pulse charge, all in one charging circuit. This work will address this issue because it is highly economical to users if the service live of batteries are high. But one might think what if a person has three batteries with different voltages to charge? Normally he has to purchase three different chargers to charge them. Gladly this work provides a cheaper way to handle this drawback. Therefore ONE does not need to waste resources, rather in this work, a charger is designed that can charge all batteries one at a time. And it is rare to see battery chargers that have adjustable voltages in them so that they can adjust to various voltages to charge various batteries. This feat brings a new contribution to all battery charger circuits.

Charging current for batteries must be chosen between one over ten $(1 / 10)$ and one over twenty $(1 / 20)$ of the battery capacity, but closer to one over ten [10].

Section 2 introduces the theoretical analysis and the design methods used in achieving the battery charger. It uses a block diagram, a flowchart and a simulation diagram to explain how the battery charger works. The design specification will explicate some of the major electrical components used and the various formulae and methods used in getting the suitable ICs for the purposed circuit will be addressed in Section 3. It will further express the different techniques used in arriving at the exact values of the different components. Section 4 shows the results of the design in pictorial view from the various periods of testing and the amount of time spent from charging the three different voltages is shown. The results of the period of charging were analyzed and compare it with other battery chargers in Section 5. Finally a conclusion was drawn of the analyzed results and it gave room for further works in Section 6.

\section{MATERIALS AND METHODS}

The battery charger was designed to charge in three different modes. This circuit actually uses a constant current which is set by the transformer. The circuit modulates the rate of charging as the battery is getting full with the help of the 555 timer by controlling the speed. The charging mode starts with the burst charge. The burst charge was the first phase of the charging of the batteries. A constant current charging was used to ensure that the voltage of the battery rises to a voltage that is determined by the characteristics of the battery. The battery will charge up to a ninety percent (90\%) State-Of-Charge, and the other ten percent (10\%) is charged using the Trickle Charge.

\subsection{Block Diagram}

The Fig 1 shows the block diagram of the Advanced Microcontroller Based Adjustable Voltage Automatic Battery Charger. The Power Supply Unit supplies power to the whole system, its power source is from a 220 volt AC mains, it is made up of a step down transformer which steps down the 220volt AC mains to 15 volts, with a current of $1.5 \mathrm{~A}$. This means that the maximum battery capacity it can charge is $15 \mathrm{Ah}$ or $1500 \mathrm{Ah}$. Due to the fact that the charging current has to be at least $10 \%$ of specified battery capacity (i.e., Ampere Hours) of the battery [9]. With the help of a step down transformer, a combination of the bridge rectifier, capacitor and voltage regulator, the $15 \mathrm{volts}$ AC is converted into 15 volts DC, then capacitor filters the voltage which is now used by other components of the circuit. This circuit also indicates there is a power in the circuit with the help of an LED when connected to mains.

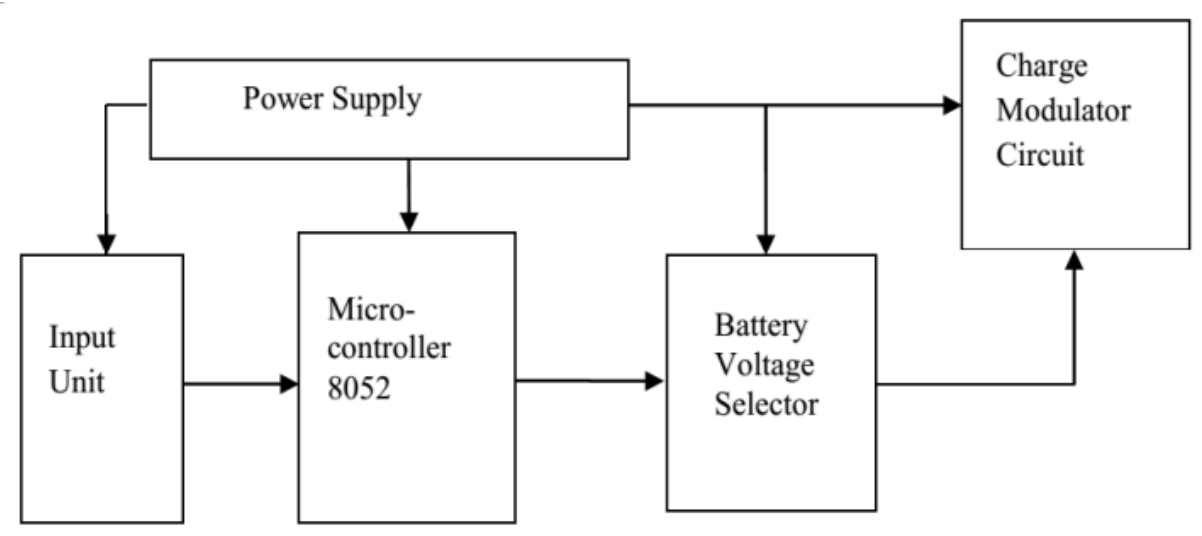

Figure1: Block diagram of the Microcontroller Based Adjustable Voltage Automatic Battery Charger 
With the press of a button, from the input unit, the user selects the desired battery voltage to be charged (between 6volt, 9volt and 12volt). The microcontroller decodes the input selected and in turn sends the appropriate signal for the particular voltage selected in the battery voltage selector, which then activates the charge modulator circuit that charges the battery. This is what postulates the actual mode of charging that the system has - the triple stage or step operation which will be switched from one to the other depending on the state of charge of the battery. To limit the current, the multivibrator integrated circuit does it automatically based on the design of the circuit. The modulation is done automatically by the battery. When the battery is full, the circuit switches to another mode of charging Pulse Charging. When the battery is not in use, the internal resistance of the battery begins to gradually sap. The pulse charge then tops the battery at every interval, (every 10 seconds). The control code for automatic battery charger is controlled by the flowchart in Figure 2.

\subsection{Simulation of the Battery Charger}

The battery charger circuit was designed using the Proteus Simulation tool. The Figure 3 shows the Simulation diagram of Advanced Microcontroller Based Adjustable Voltage Automatic Battery Charger. It is pertinent to know that the charging process was simulated using a constant current of $1.5 \mathrm{~A}$. The charging current has to be at least $10 \%$ of specified capacity (i.e. Ampere Hours) of the battery [9].

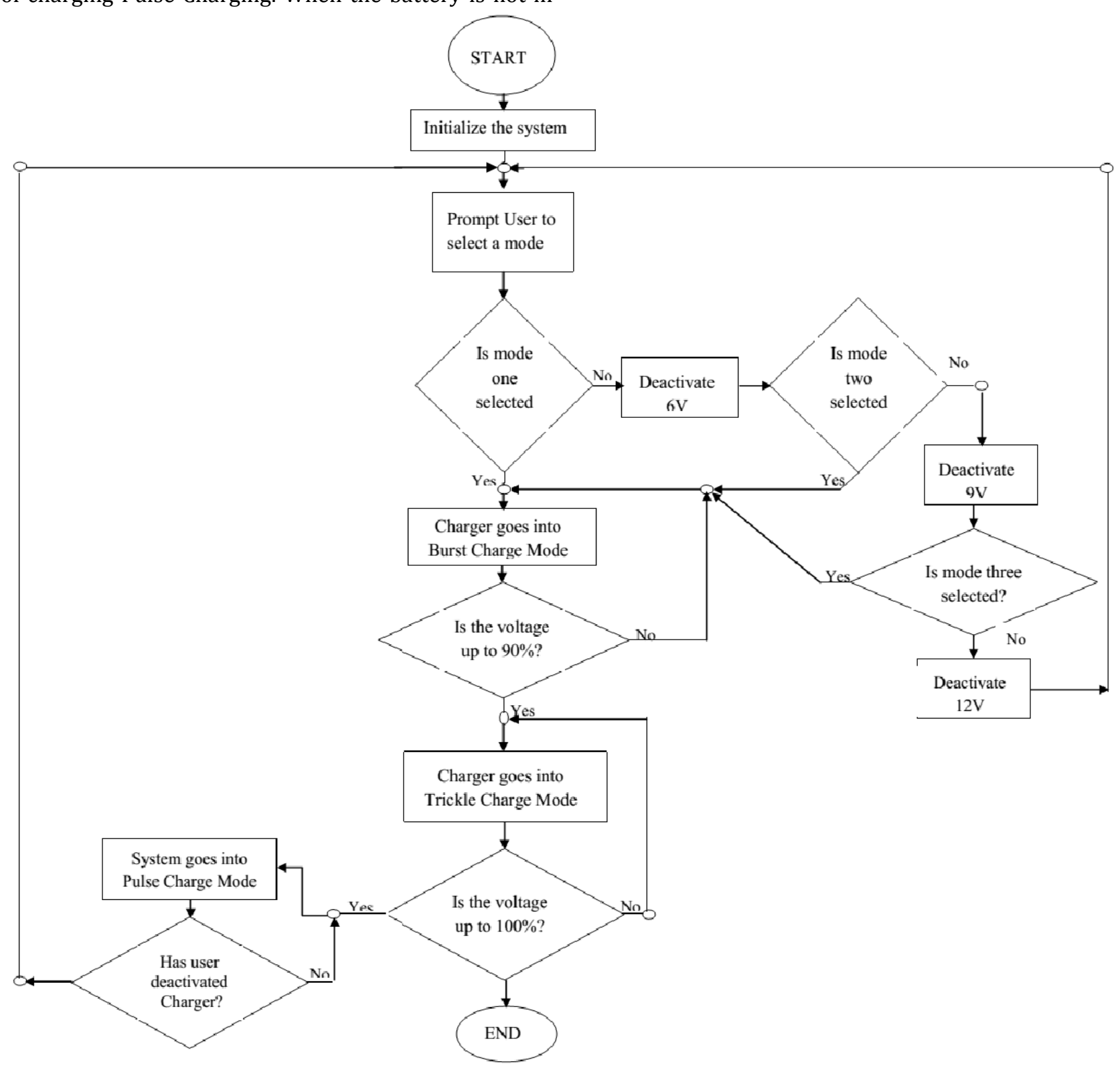

Figure 2: Flowchart for charging algorithm of the Microcontroller Based Adjustable Voltage Automatic Battery Charger 


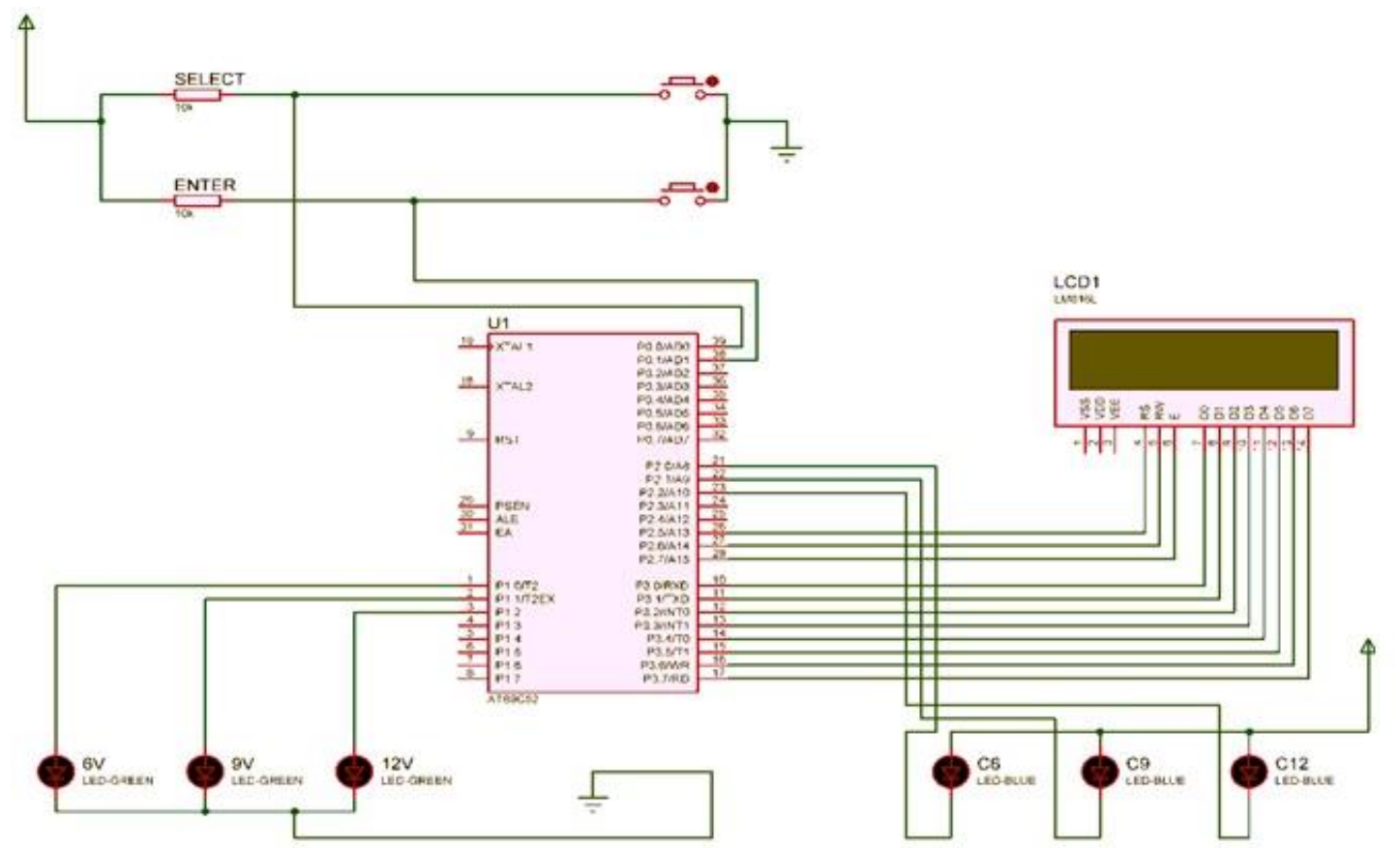

Figure3: Simulation diagram of the Microcontroller Based Adjustable Voltage Automatic Battery Charger

When a user turns on the circuit, the LCD displays the basic messages which are the name of the project, it then goes into a mode where it prompts the user to select the voltage of the battery that is about to be charged. There are two buttons; the select button is used to choose between the three various voltages a user wants to charge. When the user selects the voltage he wants to charge, he presses the enter button to accept that voltage. With the help of the microcontroller, the system automatically, moves over to the path whereby the particular battery selected will be charging. Then the LED will be lit. If the user selects 9volts for example, the two center LEDs will be lit, and this means that the adjustable voltage regulator has selected 9volts for the 555 timer to use for charging.

The three LEDs on top correspond to the selector chargers, which show the voltage has been selected by the user. They represent the transistors that select the voltage output for the adjustable voltage regulator switch on to select a particular mode. The one on top is for 6 volts, the one at the middle is for 9volts while the third one the top is for 12 volts.

The other three LEDs at the bottom of Fig. 3 tells the user which mode the charger is on at the moment. The one on top is for 6 volts; the one at the middle is for 9 volts while the third on the top is for 12 volts.

\subsection{Design Specification}

The design specification highlights some of the electronic components and other materials used to achieve the design and construction of the advanced microcontroller based adjustable voltage automatic battery charger

\subsubsection{Power Supply Unit}

This unit supplies electrical power to the charger. Its power source is from a 220volt AC mains, it is made up of a step down transformer which steps down the 220 volt AC mains to 15 volts, $1.5 \mathrm{~A}$, by this time, the voltage is still $\mathrm{AC}$. The rectifier then converts the 15 volts AC to 15 volts DC. But the DC output is a varying one. A smoothing capacitor $\mathrm{C} 1$ helps to smoothen the DC from varying greatly to a small ripple. The 15 volts DC is fed into two voltage regulators - (the fixed voltage regulator and the adjustable voltage regulator). In this subsection, attention shall be given to the fixed, while the next subsection, will be for the variable.

\subsubsection{Fixed Voltage Regulator (7805)}

The fixed voltage regulator gets rid of the remaining ripples, this is because the voltage source in a circuit may have fluctuations and would not give the fixed voltage output. Hence, it maintains the output voltage at a constant value[4]. It then produces a fixed positive voltage of 5volts DC that is used to power the microcontroller and some of the digital ICs in the circuit. This circuit also indicates there is a power in the circuit with the help of an LED when connected to mains. To use, the following conditions has to be met. (Where $\mathrm{V}_{\text {min }}, \mathrm{V}_{\text {out }}, \mathrm{V}_{\text {ref }}, \mathrm{V}_{\max }=$ Minimum, Output, Reference, \& Maximum Voltages respectively)

$\mathrm{V}_{\text {max }}=32 \mathrm{~V}$

$$
V_{\text {min }}=V_{\text {out }}+V_{\text {red }}
$$


$\mathrm{V}_{\text {ref }}=2$ or $3 \mathrm{~V}$ (from 7805 datasheet)

$\mathrm{V}_{\text {out }}=$ The expected output voltage $(5 \mathrm{v})$

Substituting the value into (1)

$\mathrm{V}_{\text {min }}=5+2=7 \mathrm{~V}$

This means that the voltage range will fall between $7 \mathrm{~V}$ to $32 \mathrm{~V}$.



Figure 4: Output regulated DC

\subsubsection{Current Limiting Resistor}

$$
R_{X}=\frac{V_{s}-V_{D}}{I_{D}} R_{1}
$$

From Fig. 5 is the current limiting resistor that protects the LED. The value is gotten from the formula: $V_{s}$ is the Voltage of supply (the 7805 outputs $5 \mathrm{v}$ ), $\mathrm{V}_{\mathrm{D}}$ is the Voltage drop across LED $=2 \mathrm{v}$ and $\mathrm{I}_{\mathrm{D}}$ is the Current through LED $(10 \mathrm{~mA}-20 \mathrm{~mA})$. It must be converted to Ampere before use.

$$
R_{1}=\frac{5-2}{0.01}=300 \Omega
$$

But 330 ohms resistor was used because it is the closest and available resistor in the market.

\subsubsection{Adjustable Voltage Regulator (LM317)}

The LM317 device was chosen because it is an adjustable three-terminal positive-voltage regulator capable of supplying more than $1.5 \mathrm{~A}$ over an outputvoltage range of $1.25 \mathrm{~V}$ to $37 \mathrm{~V}$ [3]. It is the main IC that does the voltage regulations needed. The voltage that comes from the transformer is actually 15volts DC. And this voltage is regulated based on the choice of battery voltage the user wants to charge. The LM317 will have to be able to regulate between the three voltages which are 6volts, 9volts or 12volts respectively using (1). The schematic diagram in Figure 6 shows the way the adjustable voltage regulator was connected in the circuit diagram.

The design equation for $\mathrm{V}_{\text {out }}$ using LM317 is:

$$
V_{\text {out }}=V_{\text {ref }}\left(1+\frac{R_{2}}{R_{1}}\right)
$$

Where $\mathrm{V}_{\text {ref }}=1.25 \mathrm{~V}$. When $\mathrm{V}_{\text {out }}=6 \mathrm{~V}$. If $\mathrm{R}_{1}=220 \Omega$, then the value of $R_{2}$ is found as follows:

From Eqn (3), It can be rearranged to get:

$$
R_{2}=R_{1}\left(\frac{V_{\text {out }}}{V_{\text {ref }}}-1\right)
$$

$\mathrm{R}_{2}=220 \Omega\left(\frac{6 \mathrm{~V}}{1.25}-1\right)=836 \Omega$

Notice that to charge $6 \mathrm{~V}$ battery the source voltage has to be at least higher than the battery voltage[2]. Keeping this in mind, $\mathrm{R}_{2}$ can be

$$
R_{2}=R_{1}\left(\frac{V_{\text {out }}}{V_{\text {ref }}}-1\right)=1047.2 \Omega
$$

Hence the required output voltages of 7.2 volt to charge the 6 volt battery, 10.2 volt to charge the 9 volt battery , 13.6 volt to charge the 12 volt battery. When $\mathrm{V}_{\text {out }}=9 \mathrm{~V}$, using (2), $\mathrm{R}_{2}=1575.2 \Omega$ and when $\mathrm{V}_{\text {out }}=12 \mathrm{~V}, \mathrm{R}_{2}=$ $2173.6 \Omega$

\subsubsection{Base Resistor Values}

There were some base resistors for the switching transistors. The resistors $\mathrm{R}_{6}, \mathrm{R}_{7}$, and $\mathrm{R}_{8}$. In Fig. 5 are examples of some used in the circuit. For transistor switching, the base transistor and the collector resistor has to be carefully chosen to carry out Hard Saturation. For Hard Saturation, the following formula was used:

$$
R_{B}=10 R_{c}
$$

$\mathrm{R}_{\mathrm{C}}=\mathrm{R}_{2}$ (From Figure. 5) $=$ Collector Resistor $=1000 \Omega$

$\mathrm{R}_{\mathrm{B}}=\mathrm{R}_{6}, \mathrm{R}_{7}$, or $\mathrm{R}_{8}$. Substituting into Eqn (5), $\mathrm{R}_{\mathrm{B}}=10 \times$ $1000 \Omega=10000 \Omega=10 \mathrm{k} \Omega$. Therefore $\mathrm{R}_{\mathrm{B}}=\mathrm{R}_{6}=\mathrm{R}_{7}=\mathrm{R}_{8}$ $=10 \mathrm{k} \Omega$

\subsubsection{AT89C52 Microcontroller}

The choice of the 8052 microcontroller was strategic. It was chosen ahead of over 100 different microcontrollers because of its availability, cost and expertise. Also the 8052 hardware circuit is usually a very flexible one and all the surrounding components are given a recommended range of values. The 8052 microcontroller is what coordinates and controls all activities of the system. It was programmed it using assembly language. By the datasheet but the actual values can be chosen by the programmer. The range of values given for the 8052 microcontroller hardware are as shown in Table 1:

\section{Table 1: Values of the Microcontroller Used}

\begin{tabular}{lll}
\hline Component & Ranges & Value used \\
\hline Reset capacitor & $4.7 \mu \mathrm{F}$ to $10 \mu \mathrm{F}$ & $10 \mu \mathrm{F}$ \\
& & \\
$\begin{array}{l}\text { Reset resistor } \\
\text { Crystal oscillator }\end{array}$ & $8.2 \mathrm{~K} \Omega$ to $15 \mathrm{KH} \Omega$ & $10 \mathrm{~K} \Omega$ \\
& & $12 \mathrm{MHz}$ \\
Crystal oscillator & $27 \mathrm{pH}$ to $47 \mathrm{pF}$ & $33 \mathrm{pF}$ \\
Pull-up resistors & $470 \Omega$ to $10 \mathrm{~K} \Omega$ & $1 \mathrm{~K} \Omega$ \\
\hline
\end{tabular}

For the programming of the microcontroller for the message that will be displayed on the LCD screen, the chosen values are shown in Table 1. 


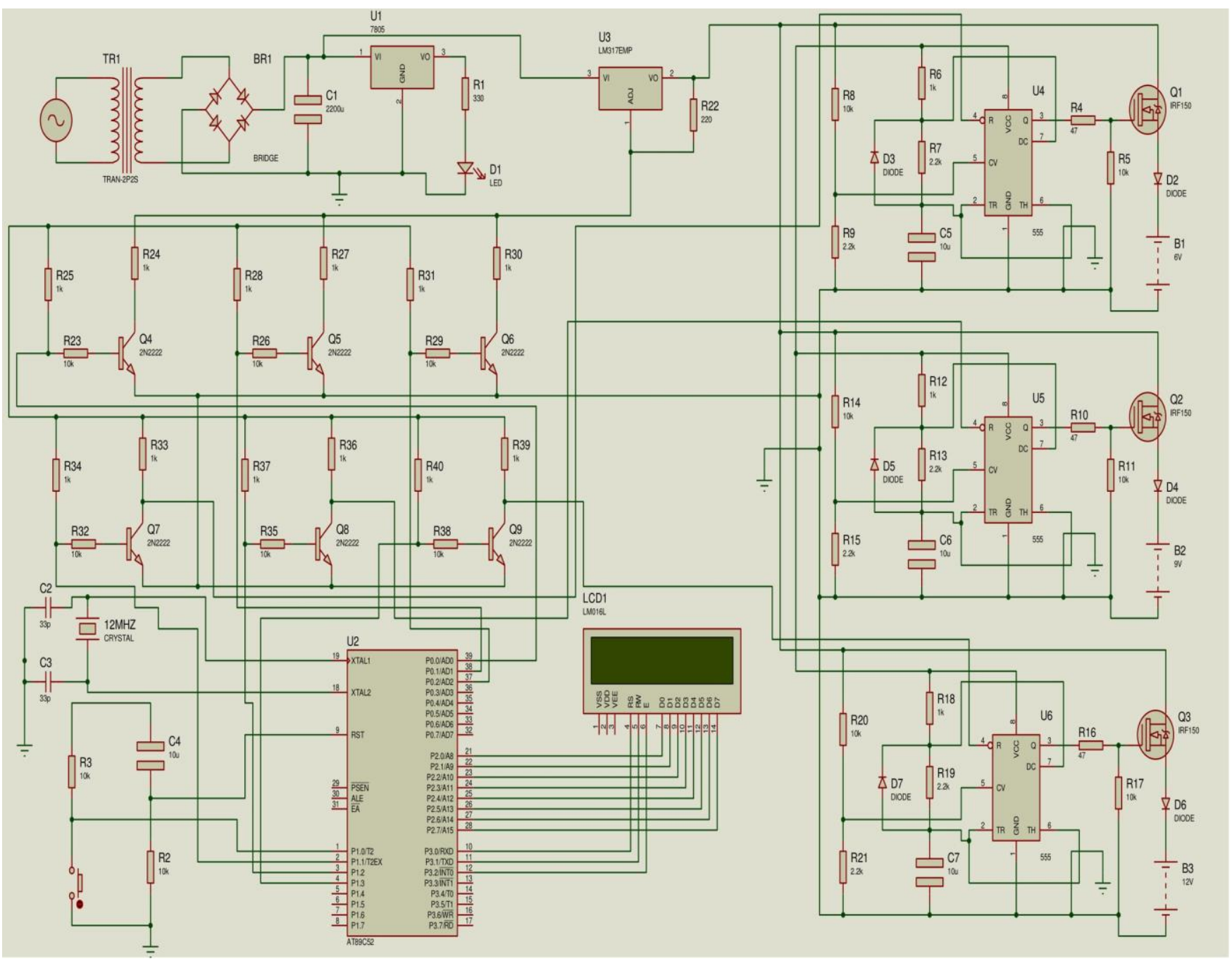

Figure 4: A complete circuit diagram of the system

\section{TEST, RESULTS AND DISCUSSION}

Figure 6 shows the final setup of the prototype battery charger. The pictures show the LED, ENTER and select Buttons. It also shows that the charger has one red crocodile clip and three black crocodile clips. The red crocodile clip is connected to the positive terminal of the battery and the three black crocodile clips are for the three different voltages (6Volts, 9 Volts and 12Volts) respectively. They cannot be used concurrently. The battery charger can actually be used to charge any kind of battery, however it is better applied to deep cycle batteries. As a result, a better and user friendly charger circuit was built, which considers the life span of the battery life by limiting overcharge and which can charge three battery voltages. After the construction of the battery charger, it was tested for several hours in a day for the period of two weeks using the three different voltages of a battery and the results for the work were as follows:

- For a 6volt battery of $10 \mathrm{Ah}$, the battery charger circuit charged the battery to $100 \%$ State-Of-
Charge for approximately 2 hours, 24 minutes (2.4 hours).

- For a 9volt battery of $1200 \mathrm{mAh}$, the battery charger circuit charged the battery a $100 \%$ StateOf-Charge for approximately 2hours, 36minutes (2.6 Hours).

- For a 12 volt battery of $10 \mathrm{Ah}$, the battery charger circuit charged the battery a $100 \%$ State-Of-Charge for approximately 2 hours, 30 minutes (2.5 hours).

From the tests carried out on the battery charger it is noticed that it took a predictable amount of time to charge the three different battery voltages. This is due to the fact that all three batteries obey the rule of thumb and the charging current is constant. But if the charging current were varying, then the time taken to achieve a $100 \%$ State-Of-Charge will definitely vary, due to the fact that what is being charged in battery is the current. 


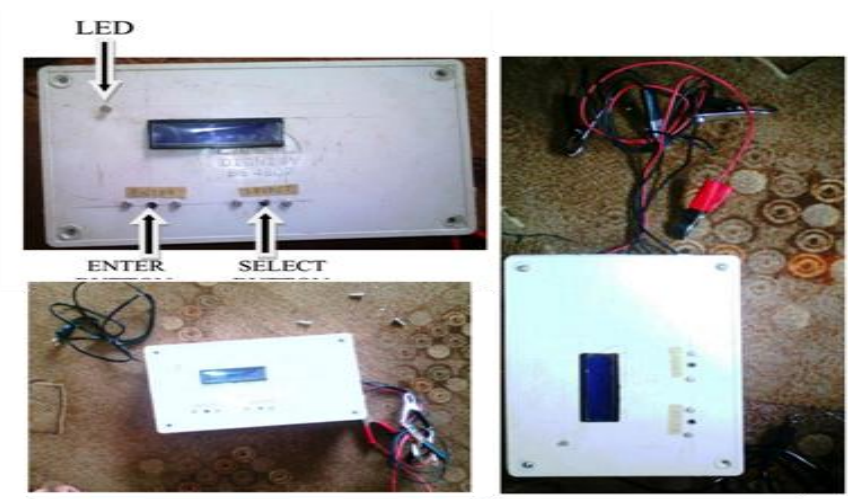

Figure 6: Microcontroller Based Adjustable Voltage Automatic Battery Charger Prototype

\section{CONCLUSION}

This work has contributed to the development of automatic battery chargers. The application of this device has a wide range from phone batteries, camera batteries, toy batteries etc. The major limitation of the work is that the current output is so small - about $1.5 \mathrm{~A}$ The different diagrams, formulae and pictures explain succinctly the working principle and the basic idea behind the design and construction of the Advanced Microcontroller Based Adjustable Voltage Automatic Battery Charger. This charger can charge major rechargeable batteries with the charging current of $1.5 \mathrm{~A}$ (rated capacity of 15Ah) or less. This is possible with the help of the microcontroller and an adjustable voltage regulator. The charger can provide the charging of three different voltages (sequentially) to 100\% SOC, prevent overcharging and stop self-discharge when the battery is connected to the charger and it is not charging. It does its charging in three modes - first the burst charge, then the trickle charge follows upon getting to $90 \%$ SOC and when full, the pulse charge begins if the battery is still connected to the charger. An LCD module is attached to make the charger user friendly. It should be noted that the three charger circuits cannot work concurrently, rather they work in a sequential manner. The Burst charging starts first, then when it gets to a particular level or percentage, the Trickle charging starts, and finally when it is not in use, the Pulse Charging is active.
A future direction on this project would be increasing the charging current of this charger because of its present limitation in terms of charging current. A buzzer could also be added to the system upon battery full.

\section{REFERENCES}

[1] A. Daoud and A Midoun Fuzzy Control of a Lead Acid Battery Charger. Journal of Electrical Systems 1-1: 52-59, 2005.

[2] Battery University Website. [Online]. Available: http://www.batteryuniversity.com retrieved on March 2016.

[3] Datasheet of LM317

[4] Datasheet of 7805

[5] Felipe Andrade Allemand Borges*, Leonimer Flávio De Mello*, Luis Carlos Mathias*, João Maurício Rosário Complete Development of An Battery Charger System With State-Of-Charge Analysis. European International Journal Of Science And Technology, Vol. 2 No. 6 July 2013.

[6] F.Vijay Amirtha Raj Automatic Battery Charging Algorithms For Hybrid Electric Vehicles. International Journal of Emerging Science And Engineering, Volume-1, Issue-2, December 2012.

[7] Karim El Khadiri And Hassan Qjidaa Design Of A Battery Charger Interface Precharge For Mobile Phone. International Journal of Embedded Systems and Applications, Vol.3, No.2, June 2013.

[8] Microcontroller Application - Battery Charger D/N: HA0052E, HOLTEK.

[9] M Pammar and S Chavan.. Design and Development of Advanced Microcontroller Based Solar Battery Charger And Solar Tracking System, International Journal of Research Engineering and Technology, Volume: 03 Special Issue: 03, May2014 pp. $36-41$.

[10] V Krishnamurthy, R Varma, S Tribhuvan, A Shaikhh. Automatic Battery Charger. International Journal of Advanced Research in Computer and Communication Engineering Vol. 3, Issue 5, May 2014, pp. 6614-6617, 2014. 